\title{
Representatives of Diplomonadida in fishes of East Siberia
}

Denikina N.N., Nebesnykh I.A., Kondratov I.G.*, Khanaev I.V., Dzyuba E.V.

Limnological Institute, Siberian Branch of the Russian Academy of Sciences, Ulan-Batorskaya Str., 3, Irkutsk, 664033, Russia

\begin{abstract}
In this study, we analyze the diversity of flagellated protozoa Diplomonadida, which are parasites in the digestive system of animals, in fishes of East Siberia. We have developed a method to diagnose the presence of DNA of Diplomonadida representatives, in particular, of Spironucleus barkhanus, in the analyzed samples. In our previous studies, we used molecular genetic methods to analyze salmonids of East Siberia for the presence of diplomonads and to determine the infection. The analysis of genetic diversity of diplomonads in the fishes of the genera Coregonus and Thymallus revealed the presence of one species, $S$. barkhanus. However, in addition to a cosmopolitan genotype widespread among Holarctic salmonids, in $C$. migratorius and $C$. lavaretus baicalensis, we have found a new genotype obviously different from those registered previously. Probably, $S$. barkhanus of this genotype is endemic for Lake Baikal. To determine a probable parasite exchange between $C$. migratorius and other fish species in the pelagic zone of Lake Baikal, we performed a screening of near-shore pelagic and pelagic cottoid fish for the presence of $S$. barkhanus. The analysis did not indicate the presence of DNA of $S$. barkhanus in the studied samples. We suppose the presence of other diplomonads species in endemic cottoid fish different from $S$. barkhanus.
\end{abstract}

Keywords: molecular genetic methods, Lake Baikal, Coregonus, Thymallus, Comephorus, Cottocomephorus

Diplomonadida are the flagellated protozoa that for many years have been considered the most primitive of eukaryotes, since they lack the typical mitochondria, peroxisomes and the Golgi apparatus (Keeling and Doolittle, 1997). The discovery of several varieties of mitochondria in Diplomonadida revealed that their cells were secondarily simplified, and these protists cannot be an intermediate stage in the formation of organelles in the general scheme of the evolutionary history of eukaryotes (Jerlstrom-Hultqvist et al., 2013). The order Diplomonadida includes the genera Spironucleus, Hexamita, Trepomonas, Trimitus, Enteromonas, Octomitus, and Giardia (Kolisko et al., 2008). The species Hexamita are mostly free-living anaerobic organisms inhabiting bottom sediments. At the same time, other taxa are almost purely commensals and pathogens, which usually inhabit the digestive system of mammals, birds, reptiles, amphibians, arthropods, molluscs, and fishes (Williams et al., 2011).

Diplomonads are of special interest for veterinary and agricultural organisations due to the severe pathologies that they cause in bred animals. Species of the genus Spironucleus are of particular attention, since they can cause devastating episodes of systemic infections in both ornamental and commercial fishes. These ubiquitous flagellates are found in cold, temperate and tropic waters and can infect a wide range of freshwater and marine fishes, as well as molluscs and crustaceans (Noga, 2010). The fish industry (and aquaculture in general) is becoming increasingly important in the world, since the natural fish stocks are depleted. At the same time, fishes and other objects of aquaculture are especially susceptible to outbreaks of diseases caused by diplomonads. For instance, Spironucleus salmonicida Jorgensen \& Sterud, 2006 caused massive episodes of systemic infections in the farm-raised Salmo salar Linnaeus, 1758 and Oncorhynchus tshawytscha (Walbaum, 1792) (Kent et al., 1992; Poppe and Mo, 1993). The life cycle of diplomonads is direct and includes the stage of mobile parasitic trophozoite, which is generally followed by a stage of cysts. Infection rate is extremely high, especially in aquaculture, which also leads to a significantly high risk of host death.

The biology and ecology of species of the genus Spironucleus are poorly investigated in many aspects, including specific hosts, geographic ranges, transmission mechanisms, and pathogenicity of different species. Lack of knowledge is a serious limitation in disease control, since it impedes an accurate diagnosis and identification of the infection source. These obstacles are primarily associated with difficult detection of the genera and species of the order Diplomonadida, 
which also explains the confusion in the nomenclature. The descriptions of the diplomonads are incomplete. Morphological studies using scanning and transmission microscopy often do not allow accurate identification of species. For example, Spironucleus barkhanus Sterud, Mo, \& Poppe, 1998 has been described for a long time as eukaryotic organism of two morphologically similar types (nonpathogenic freshwater and pathogenic marine) (Sterud et al., 1998). Based only on the molecular genetic analysis, the representatives of this pathogenic genotype were described as a new species (S. salmonicida). Subsequently, the gene sequences of the small subunit ribosomal DNA were determined for all known species of diplomonads isolated from fishes and belonging to the genus Spironucleus: $S$. barkhanus, $S$. salmonicida, $S$. salmonis, $S$. torosa, and $S$. vortens. Previously, they were studied by ultrastructure analysis (Jørgensen and Sterud, 2006). Therefore, molecular genetic analysis plays a key role in detection and a correct identification of diplomonads in fishes.

Despite the relatively high level of knowledge about animals of Lake Baikal and water bodies of East Siberia, data on the species composition of parasitic protozoa are still fragmentary and incomplete. Previously, representatives of the genus Hexamita were described by morphological characteristics in Coregonus migratorius (Georgi, 1775), Thymallus baicalensis Dybowski, 1874, Thymallus brevipinnis Svetovidov, 1931, Leuciscus baicalensis (Dybowski, 1874), Lota lota (Linnaeus, 1758), and endemic cottoid fish: Batrachocottus multiradiatus Berg, 1907, Batrachocottus nikolskii (Berg, 1900), Cottocomephorus grewingkii (Dybowski, 1874), and Limnocottus bergianus (Taliev, 1935) (Zaika, 1965; Pronin, 2001; Pugachev, 2001; Rusinek, 2007).

Nucleotide sequences of a gene fragment of the small subunit ribosomal RNA were obtained in the study of the microbiota from the intestinal tract of $T$. baicalensis from the Angara River. These sequences were identical to $S$. barkhanus from Thymallus thymallus (Linnaeus, 1758) and Salvelinus alpinus (Linnaeus, 1758) (Belkova et al., 2008; 2009). Based on the sequences obtained, a diagnostic system was developed allowing detection of diplomonads and determination of their species (genotype).

In this study, we performed molecular genetic studies by standard methods: DNA was extracted using a DNA-Sorb-B kit according to the manufacturer's instructions (Ampli-Sens, Moscow); PCR was carried

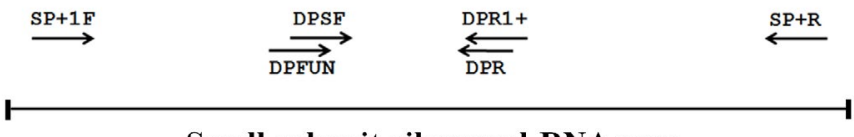

Small subunit ribosomal RNA gene

Fig. 1. Schematic arrangement of primers on the gene sequence of the small subunit rRNA

out in a standard reaction mixture.

The regions conservative for eukaryotes (DpFun-DpR) served as primer to diagnose the presence of DNA of diplomonads. At the same time, the difference in the length of the observed gene fragment in diplomonads ( $\sim 450 \mathrm{bp})$ and other eukaryotic organisms ( $\sim 630$ and more) provided the specificity of the target amplicons. Gene fragments of the small subunit rRNA of $S$. barkhanus were amplified using speciesspecific primers developed and tested in this study (Table 1, Fig. 1).

Using the developed diagnostic system, we determined infection in the representatives of the genera Coregonus and Thymallus (Denikina et al., 2011; 2016; 2017).

The representatives of the genus Thymallus occupy a large area of unconnected basins of the Palaearctic and Nonarctic rivers and lakes. Analysis of fish of the genus Thymallus from water bodies of East Siberia and Mongolia has shown an obvious trend in infection of graylings $S$. barkhanus in the catchment area of the Angara River: the minimum in Lake Khubsugul (38.5\%), the significant amount in the Barguzin River and Lake Baikal (80.0 and 85.2 \%, respectively) and the maximum in the Angara River (100\%) (Denikina et al., 2011).

The genus Coregonus in water bodies of southeastern Siberia is represented by species that occupy different ecological niches and have different food strategies. $S$. barkhanus infection rate in C. migratorius varies from 29.3 to $76.2 \%$. Coregonus lavaretus baicalensis Dybowski, 1874 is slightly infected (10-20\%). The infection rate of Coregonus species in the Barguzin River was $12.5 \%$, in the tributaries of the Lena River is even lower. Therefore, habitat conditions, food preferences, behaviour and morphological features of the jaw structure are the determining factors of infection (Denikina et al., 2016).

Analysis of the genetic diversity of diplomonads in fish of the genera Coregonus and Thymallus revealed

Table 1. Primer pairs used in the study

\begin{tabular}{|c|c|c|}
\hline Direct primer sequence & Reverse primer sequence & $\begin{array}{c}\text { Amplicon } \\
\text { length (bp) }\end{array}$ \\
\hline DPFUN 5'-GCCAGCAGCCGCGGTAATTCC & DPR 5'-AGCCGCAGACTCCACRTCT & 450 \\
DPSF 5'- CAGCCGCGGTAATTCCGACAC & DPR1 + 5'-AGCCGCAGACTCCACGTCTGGTGG & 450 \\
DPSF 5'- CAGCCGCGGTAATTCCGACAC & Sp + R 5'-GCAGCCTTGTTACGACTTCTCC & 984 \\
Sp + 1F 5'-GCCATGCATGCCTATGTGTAGAC & DpR1 + 5'- AGCCGCAGACTCCACGTCTGGTGG & 881 \\
\hline
\end{tabular}


the presence of a single species of $S$. barkhanus. At the same time, along with the cosmopolitan genotype, which is widespread in salmonid fish of Holarctic, in C. migratorius and C. lavaretus baicalensis we found a new genotype significantly different from all previously recorded ones. $S$. barkhanus of this genotype is likely to be endemic for Lake Baikal (Denikina et al., 2016; 2017).

To identify a possible parasite exchange between C. migratorius and other fish species in the pelagic zone of Lake Baikal, we screened the coastal-pelagic and pelagic cottoid fish for the presence of $S$. barkhanus. To investigate the infestation of endemic species of cottoid fish, we collected the material from 25 May to 15 June 2011 throughout the entire water area of Lake Baikal. The fishes were collected with an RK-15/30 midwater trawl at different depths. In total, we investigated 27 specimens of Comephorus dybowski Korotneff, 1905, 5 specimens of Comephorus baicalensis (Pallas, 1776), 11 specimens of Cottocomephorus inermis (Jakowlew, 1890), 58 specimens of Cottocomephorus grewingkii (Dybowskii, 1874), and 60 specimens of Cottocomephorus alexandrae Taliev, 1935 (Table 2, Fig. 2).

The necessity of these experiments was due to the following circumstances. i) Along with C. migratorius, five endemic Cottoidei species inhabit the open pelagic zone of Lake Baikal: pelagic species (C. baicalensis and C. dybowski) and three benthopelagic species of the genus Cottocomephorus ( $C$. inermis, $C$. grewingkii and $C$. alexandrae). The habitats of these species coincide with those of $C$. migratorius in the winter and spring period. ii) The food spectra of these species are similar with the food spectrum of $C$. migratorius in the feeding period and includes zooplankton: Epischura baikalensis Sars, 1900 and Macrohectopus branickii (Dybowsky, 1874). iii) $T$. baicalensis inhabit the coastal zone of Lake Baikal, where bentopelagic cottoid fish spawn. There is evidence of the finding of Hexamita in C. grewingkii (Zaika, 1965). Since species determined in 1965 is rather ambiguous considering the revised classification, and the indicated localization (the intestine and gallbladder) corresponds to $S$. barkhanus, the analysis was necessary. All abovementioned ecological features of cottoid fish inhabiting the pelagic zone of the lake suggest that they have diplomonads, which were previously found in $T$. baicalensis and $C$. migratorius. However, the analysis did not reveal the presence of $S$. barkhanus in the studied DNA samples. The presence of Hexamita in $C$. grewingkii (Zaika, 1965) and the absence of $S$. barkhanus in our samples can be explained by the fact that the fish studied differed greatly. Most likely, in (Zaika, 1965) fish for parasitological analysis were collected from the coastal zone of Lake Baikal. C. grewingkii is the most numerous representative of the shallow water ichthyocenosis. Within a species, three spawning populations (schools) are distinguished at different times: March, May, and August (Taliev, 1955; Koryakov, 1972). Multi-layer rocky grounds in the coastal zone of the lake serve for $C$. grewingkii as a substrate for spawning. In schools of $C$. grewingkii spawning at different times, the incubation period for the development of clutches

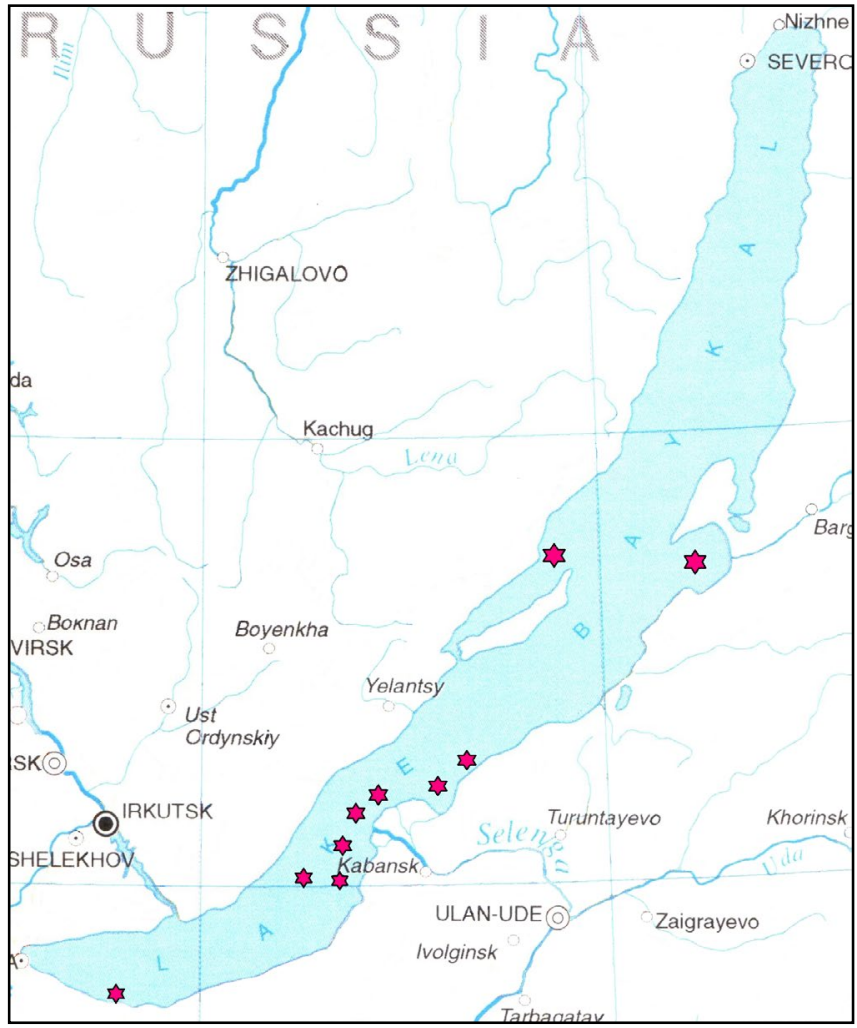

Fig. 2. Schematic sample collection map, May-June 2011

Table 2. Specimens of cottoid fish, Lake Baikal May-June 2011

\begin{tabular}{|c|c|c|}
\hline Trawl coordinates & Fish species & $\begin{array}{l}\text { Quantity, } \\
\text { specimen }\end{array}$ \\
\hline \multirow{2}{*}{$\begin{array}{c}51^{0} 51^{\prime} 17^{\prime \prime} \mathrm{N} \\
104^{0} 37^{\prime} 39 \text { "E }\end{array}$} & C. dybowski & 5 \\
\hline & C. baicalensis & 3 \\
\hline $\begin{array}{c}52^{\circ} 03 ' 67^{\prime \prime N} \\
106^{0} 02 ' 15^{\prime \prime E}\end{array}$ & C. dybowski & 5 \\
\hline \multirow{3}{*}{$\begin{array}{l}52^{\circ} 08^{\prime} 94^{\prime \prime} \mathrm{N} \\
105^{0} 81^{\prime} 32^{\prime \prime} \mathrm{E}\end{array}$} & C. baicalensis & 2 \\
\hline & C. alexandrae & 10 \\
\hline & C. inermis & 3 \\
\hline $\begin{array}{c}52^{0} 25^{\prime} 46^{\prime \prime} \mathrm{N} \\
106^{0} 02^{\prime} 41^{\prime \prime} \mathrm{E}\end{array}$ & C. grewingkii & 10 \\
\hline $\begin{array}{c}52^{0} 466^{\prime} 53^{\prime \prime} \mathrm{N} \\
106^{0} 67^{\prime} 59 " \mathrm{E} \\
\end{array}$ & C. dybowski & 5 \\
\hline $\begin{array}{c}52^{0} 58^{\prime} 42^{\prime \prime N} \\
106^{\circ} 97^{\prime} 38^{\prime \prime} \mathrm{E} \\
\end{array}$ & C. inermis & 1 \\
\hline $\begin{array}{c}53^{0} 43 \text { '39”N } \\
108^{\circ} 68^{\prime} 59 " \mathrm{E} \\
\end{array}$ & C. inermis & 3 \\
\hline $\begin{array}{c}53^{0} 46 ' 57^{\prime \prime} \mathrm{N} \\
107^{0} 60^{\prime} 67^{\prime \prime} \mathrm{E}\end{array}$ & C. inermis & 3 \\
\hline \multirow{3}{*}{$\begin{array}{l}52^{0} 38^{\prime} 64^{\prime \prime} \mathrm{N} \\
106^{0} 18^{\prime} 06^{\prime \prime} \mathrm{E}\end{array}$} & C. alexandrae & 30 \\
\hline & C. grewingkii & 20 \\
\hline & C. inermis & 1 \\
\hline \multirow{3}{*}{$\begin{array}{c}52^{0} 31^{\prime} 85^{\prime \prime} \mathrm{N} \\
106^{0} 05^{\prime} 97^{\prime \prime} \mathrm{E}\end{array}$} & C. grewingkii & 28 \\
\hline & C. alexandrae & 20 \\
\hline & C. dybowski & 12 \\
\hline
\end{tabular}


ranges from 20 to 80-90 days depending on spawning season and temperature conditions during the development of eggs. Male protects the clutch from the moment of spawning to the appearing of larvae. Most males die after the period of clutch protection. This zone is the main feeding ground for the $T$. baicalensis, which infection rate reaches $85.2 \%$. We assumed that $C$. grewingkii samples with Hexamita (Zaika, 1965) were collected in the spawning area. Therefore, we did not detect $S$. barkhanus in the open pelagic zone of the lake in the fattening $C$. grewingkii specimens. It is also likely that diplomonads in salmonid and cottoid fish were attributed to the same species by mistake, since previous data by (Zaika, 1965) were obtained using methods of light microscopy. In this case, cottoid fish may have other diplomonads species than $S$. barkhanus. This assumption requires additional studies.

\section{Acknowledgments}

This research was supported by the State Project No. 0345-2016-0002.

\section{References}

Belkova N.L., Dzyuba E.V., Sukhanova E.V. 2008. Molecular-genetic detection of a nonpathogenic genotype of Spironucleus barkhanus (Diplomonadida: Hexamitidae) in the black Baikal grayling (Thymallus arcticus baicalensis Dybowski, 1874). Biology Bullutin 35: 219-221. DOI: $10.1134 /$ S1062359008020179

Belkova N.L., Dzyuba E.V., Sukhanova E.V. 2009. Molecular-genetic identification of the intestinal microflora and protozoa of the baikalian fish. In: Timoshkin O.A. (Ed.), Index of animal species inhabiting Lake Baikal and its catchment area. Vol. 2. Novosibirsk: Nauka. (In Russian)

Denikina N.N., Nebesnykh I.A., Sukhanova E.V. et al. 2011. Development and approbation of detection method of the Diplomonadida order for the fish infection research. Biologicheskiye nauki Kazakhstana [Biological sciences of Kazakhstan] 4: 28-33. (in Russian)

Denikina N., Nebesnykh I., Maikova O. et al. 2016. Genetic diversity of Diplomonadida in fish of the genus Coregonus from East Siberia. Acta Parasitologica 61: 299-306. DOI: 10.1515/ap-2016-0040.

Denikina N.N., Nebesnykh I.A., Belkova N.L. et al. 2017. The genetic diversity of the Diplomonadida and the infection of the genera Coregonus and Thymallus of Eastern Siberia. Map № 144.4. In: Plusnin V.M. (Ed.), Ecological atlas of the Baikal region. [http://atlas.isc.irk.ru] (In Russian)

Jerlstrom-Hultqvist J., Einarsson E., Xu F. et al. 2013.
Hydrogenosomes in the diplomonad Spironucleus salmonicida. Nature communications 4: 2493. DOI: $10.1038 /$ ncomms3493 |www.nature.com/naturecommunications

Jørgensen A., Sterud E. 2006. The marine pathogenic genotype of Spironucleus barkhanus from farmed salmonids redescribed as Spironucleus salmonicida n. sp. Journal of Eukaryotic Microbiology 53: 531-541. DOI: 10.1111/j.1550-7408.2006.00144.x

Keeling P.J., Doolittle W.F. 1997. Widespread and ancient distribution of a noncanonical genetic code in Diplomonads. Molecular Biology and Evolution 14: 895-901. DOI: 10.1093/ oxfordjournals.molbev.a025832

Kent M.L., Ellis J., Fournie J.W. et al. 1992. Systemic hexamitid infection in seawater pen-reared chinook salmon. Diseases of Aquatic Organisms 14: 81-89. DOI: 10.3354/ dao014081

Kolisko M., Cepicka I., Hampl V. et al. 2008. Molecular phylogeny of diplomonads and enteromonads based on SSU rRNA, alpha- tubulin and HSP90 genes: Implications for the evolutionary history of the double karyomastigont of diplomonads. BMC Evolutionary Biology 8: 205. DOI: 10.1186/1471-2148-8-205

Koryakov E.A. 1972. Pelagic sculpins of Baikal. Moscow: Nauka. (In Russian)

Noga E.J. 2010. Fish disease- diagnosis and treatment. 2nd edition. Wiley-Blackwell.

Poppe T., Mo T.A. 1993. Systemic, granulomatous hexamitosis of farmed Atlantic salmon: interactions with wild fish. Fisheries Research 17: 147-152. DOI: doi. org/10.1016/0165-7836(93)90014-X

Pronin N.M. 2001. Polymastigotes (Mastigophora: Polymastigota). In: Timoshkin O.A. (Ed.), Index of animal species inhabiting Lake Baikal and its catchment area. Vol. 1. Novosibirsk: Nauka. (In Russian)

Pugachev O.N. 2001. Catalog of parasites in freshwater fish of Northern Asia. Protozoa. Saint Petersburg: ZIN RAS. (In Russian)

Rusinek O.T. 2007. Fish parasites of Lake Baikal (fauna, communities, zoogeography and historical background). Moscow: KMK Scientific Press Ltd. (In Russian)

Sterud E., Mo T.A., Poppe T.T. 1998. Systemic spironucleosis in sea-farmed Atlantic salmon Salmo salar, caused by Spironucleus barkhanus transmitted from feral Arctic char Salvelinus alpinus? Diseases of Aquatic Organisms 33: 63-66. DOI: $10.3354 /$ dao033063

Taliev D.N. 1955. Baicalian sculpins (Cottoidei). Moscow-Leningrad: Publishing House of the USSR Academy of Sciences. (In Russian)

Williams C., Lloyd D., Poynton S. et al. 2011. Spironucleus species: economically-important fish pathogens and enigmatic single-celled Eukaryotes. Journal of Aquaculture Research and Development S2-13. DOI: dx.doi.org/10.4172/2155-9546.

Zaika V.E. 1965. Parasitofauna of Lake Baikal fishes. Moscow: Nauka. (In Russian) 